\title{
Inhaltsverzeichnis
}

Abkürzungsverzeichnis . . . . . . . . . . . . . . . . . IX

Literaturverzeichnis . . . . . . . . . . . . . . . XI

Einleitung . . . . . . . . . . . . . . . . . . . . . 1

Erster Teil:

Organisationsstruktur und innergewerkschaftliche Wiliensbildung . . . 4

$\S 1$ Allgemeine Gliederung der Einzelgewerkschaften und des DGB . 4

I. Einzelgewerkschaften . . . . . . . . . . . . . . 6

$\S 2$ Erwerb der Mitgliedschaft . . . . . . . . . . . . . . 6

a) Verfahren . . . . . . . . . . . . . . . . . . . . . 6

b) Ablehnungsgründe . . . . . . . . . . . . . . . . . . . . . . 7

§ 3 Verlust der Mitgliedschaft . . . . . . . . . . . . . . . 10

a) Gründe für Ordnungs- und Ausschlußverfahren . . . . . . . 10

b) Ordnungs- und Ausschlußverfahren . . . . . . . . . . . . . 13

§ 4 Amtserwerb auf Ortsebene . . . . . . . . . . . . . . 16

a) Wahl der Vertrauensleute . . . . . . . . . . . . . . . 16

b) Wahl der Delegierten . . . . . . . . . . . . . . . . . . 17

c) Wahl des Verwaltungsstellenvorstandes . . . . . . . . . 18

$\S 5$ Amtserwerb auf Bezirksebene . . . . . . . . . . . . . . . 25

a) Bezirkstag bzw. Landesbezirkskonferenz . . . . . . . . 25

b) Wahl des Bezirks- bzw. Landesbezirksvorstandes . . . . . . . 26

$\S 6$ Amtserwerb auf Bundesebene . . . . . . . . . . . . 31

a) Gewerkschaftstag . . . . . . . . . . . . . . . . . . . 31

b) Gewerkschaftsbeirat . . . . . . . . . . . . . . . . . 32

c) Beschwerdeausschuß . . . . . . . . . . . . . . 34

d) Hauptvorstand . . . . . . . . . . . . . . . . . . . . . . 35

§ 7 Zuständigkeitsverteilung und Möglichkeiten der Mitwirkung auf Ortsebene . . . . . . . . . . . . . . . . . . . 41

§ 8 Zuständigkeitsverteilung auf Bezirks- bzw. Landesbezirksebene . 45

$\S 9$ Zuständigkeitsverteilung auf Bundesebene . . . . . . . . 48 
$\S 10$ Aufbau der Fachgruppen . . . . . . . . . . . . . . . 58

$\S 11$ Aufbau der Personengruppen . . . . . . . . . . . . . 61

$\S 12$ Durchführung der Tarifverhandlungen und der Arbeitskämpfe . . 63 II. Deutscher Gewerkschaftsbund . . . . . . . . . . . 67

§ 13 Aufbau der Kreisebene . . . . . . . . . . . . . . . . . 68

$\S 14$ Aufbau der Landesbezirksebene . . . . . . . . . . . . 70

$\S 15$ Aufbau der Bundesebene . . . . . . . . . . . . . . 72

Zweiter Teil:

Anforderungen des Grundgesetzes an den Aufbau der Gewerkschaften . 76

$\S 16$ Einschränkungen der Verbandsautonomie durch das BGB . . . 77

$\S 17$ Die Methode der Verfassungsinterpretation . . . . . . . . 86

§ 18 Öffentliche Funktionen der Gewerkschaften . . . . . . . . . . 91

$\S 19$ Verfassungstheoretische Untersuchung über die Stellung der Verbände im Staatsgefüge . . . . . . . . . . . . . . 104

$\S 20$ Einschränkung der Verbandsautonomie durch die Lehre von der Drittwirkung der Grundrechte . . . . . . . . . . . . 115

§ 21 Ubertragung verfassungsrechtlicher Grundprinzipien auf Verbände 123

§ 22 Abgrenzung der betroffenen Verbände . . . . . . . . . 138

§23 Freiheitlich demokratische Grundordnung . . . . . . . . 144

$\S 24$ Demokratische Grundsätze in Parteien und Verbänden . . . . 148

\section{Dritter Teil:}

Entspricht die satzungsgemäße und tatsächliche Situation in den

Gewerkschaften diesen Demokratiekriterien? . . . . . . . . . 153

$\S 25$ Funktion der Satzung . . . . . . . . . . . . . . . . 153

$\S 26$ Gliederung der Gewerkschaften . . . . . . . . . . . . 156

$\$ 27$ Der Zugang zu den Gewerkschaften . . . . . . . . . . 162

$\S 28$ Gleiche Mitwirkungsrechte aller Mitglieder . . . . . . . . 171

§ 29 Beendigung der Mitgliedschaft . . . . . . . . . . . . 177

$\S 30$ Zuständigkeitsverteilung zwischen Mitgliedern, ihren Organen und dem Vorstand . . . . . . . . . . . . . . . . 183

$\S 31$ Anforderungen an die Delegiertenversammlungen . . . . . . 189

$\S 32$ Wahl des Vorstandes . . . . . . . . . . . . . . . 193

$\S 33$ Die Rechtsstellung der Gewerkschaftsvertreter in außergewerkschaftlichen Gremien . . . . . . . . . . . . . . . 195

Sachregister . . . . . . . . . . . . . . . . 198

Personenregister . . . . . . . . . . . . . . . . . 200 